\title{
Students as leaders in open access advocacy \\ The story of the University of Washington initiative
}

$\mathbf{T}$ his is the story of ongoing student efforts to realize an open access (OA) policy at the University of Washington (UW). Among other superlatives, UW receives more federal research dollars $^{1}$ than any other public university in the nation-making it a logical place for an initiative to facilitate free and public access to scholarly outputs. In 2014, UW received $\$ 1.39$ billion in funding - a 12\% increase from 2013. Like other large U.S. universities, UW also hosts diverse faculty interests, an understaffed and underfunded institutional repository, and highly active student and faculty governments - but also, as we have come to find, an organic, self-assembled student interest in OA.

We did not know any of that, however, when we-a law student and an information science graduate student with deeply held values of equity, access, and openness-started an OA initiative at UW about two years ago. All we knew was that the idea of OA seemed like a nobrainer. Researching OA policies and practices at comparable U.S. institutions confirmed this intuition. The overwhelming sentiment between us was, "Why doesn't the UW have this already?"

We took this sentiment to the student government and immediately set about drafting a policy. We envisioned a Harvard-style policy ${ }^{2}$ with noncoercive, clear opt-out options and robust institutional support, accompanied by committed school- and department-level follow-ups. With scant experience in university government, we drafted a heavy-handed, four-page policy. We handed it to supportive UW librarians for review, and got raised eyebrows in return.
This gave us a much-needed wake-up call. We had thought that reading up on other universities' policies and committing key OA advocacy tenets to memory (Education! Expectations! Assistance! Incentives! Infrastructure!) were enough, but we quickly learned that we would have to promote those tenets to the university before any policymaking could take place.

Following this first policy attempt, we shifted our focus from drafting policy to engaging our colleagues-fellow students. We had conversations with student government leadership about the importance of $\mathrm{OA}$ at a university as large as ours, and about the unique ways OA can benefit students and early-career researchers. Once we marshaled support from the student leadership, we put OA on the student government agenda. Our priority was to gain support not only from the student body presidents, but also from student representatives across all departments. Accordingly, we drafted student resolutionsperhaps the best way to codify unanimous student agreement-in support of OA. We passed a resolution ${ }^{3}$ in the Graduate and Professional Student Senate (GPSS) in January 2015, and a

Gennie Gebhart is library and information science master's student (2016), email: gennie@ uw.edu, and Juliya Ziskina is law student (2016) at University of Washington, email: jziskina@uw.edu

Contact series editors Adrian Ho, director of digital scholarship at the University of Kentucky Libraries, and Patricia Hswe, digital content strategist at Penn State University, at crlnscholcomm@gmail.com with article ideas.

๑ 2015 Gennie Gebhart and Juliya Ziskina 
mirror resolution ${ }^{4}$ in the Associated Students of the University of Washington (ASUW), the undergraduate student body, in March. Both student bodies voted unanimously in favor.

Student reactions to OA were open-minded and brought up sophisticated questions and frank conversations. Different academic fields brought different concerns. For instance, a neuroscience student asked about the implications of open data, and an English student asked about copyright. However, the common thread was that students tended to know more about the mechanics of OA and inherent issues than many faculty did. Students and early-career researchers were worried about more than a citation boost, they were concerned with the terms under which they would begin their careers.

In large part, our success with students (and later with faculty) hinged on the support of librarians and experts. Throughout this initiative, the UW Libraries has been a crucial voice in educating both faculty and students about OA. In the GPSS voting meeting, for example, librarians fielded technical questions, represented the UW Libraries, and lent credibility to OA ideas that many students were encountering for the first time. While the emphasis remained on student-led decision-making, the active presence of library staff signaled a united commitment to moving this cause forward.

We also sought advice from external experts. The Scholarly Publishing and Academic Resources Coalition (SPARC), the Right to Research Coalition (R2RC), the Harvard Open Access Project (HOAP), and Creative Commons were valuable resources as we consulted with faculty and wrote what we believe is one of the most comprehensive OA FAQs ${ }^{5}$ on the web.

With widespread student support secured, we sought allies in different parts of the university. The GPSS and ASUW resolutions were critical backup as we brought OA up for faculty consideration. Everything we accomplished from this point built on these two resolutions, and they remain the central foundation for the OA initiative at UW.

Our first step was to assert the OA initiative as a constant, vocal presence at faculty council meetings, especially those of the Faculty Council on University Libraries and the Faculty Council on Research. Not only did we find faculty supporters with similar goals this way, we also gathered unified support from both of these groups. They became a nexus of support, encouragement, and brainstorming - not to mention influence on other faculty. As much as we would like to, students cannot implement OA on our own. The robust OA policy we envision calls for support across all levels of the university. Reaching out to faculty councils was the bridge between student momentum and faculty engagement.

We would not have gotten very far among faculty if we had not had a faculty champion to present the idea of OA to faculty groups. As students, we had to be cognizant of our position in the university structure. This did not mean we did not have a voice, but it did mean that we needed to be aware of where and how our voices were most effective. A faculty champion is in a much better position to talk to other faculty members about the specifics of their profession-in this case, incorporating OA into workflows and norms.

We learned quickly_ and are still learninghow to be faculty members' greatest supporters and assistants. This means balancing student energy and knowledge with their experience, expertise, and stake in the issue.

Most recently, on April 23, 2015, the UW Faculty Senate unanimously passed an OA resolution, ${ }^{6}$ calling for a university-wide policy and resources to improve UW's repository, ResearchWorks. The resolution, while not binding, expresses faculty support for an OA policy. Although it does not detail the specific mechanisms of an OA policy (such as a nonexclusive license, a clear opt-out option, and applicability to both faculty and students), it does call upon the vice provost of digital initiatives (our hugely supportive dean of libraries, Betsy Wilson) to prepare a policy for recommendation to the UW president, with input from campus stakeholder groups. Headed by our faculty champion, the Faculty Councils on University Libraries and on Research combined efforts to draft the resolution. As students, we had an important say in the ideas behind the resolution, but it was ultimately and appropriately written by faculty—not by us. 
However, our work as students was not done. We contacted all OA-supportive faculty members we knew (or knew of) and informed them about the Faculty Senate voting meeting. We "recruited" as many faculty members as possible to be present and steer the conversation into friendly territory, if necessary. Indeed, the success of the Faculty Senate vote hinged on how the conversation was framed. It was important that faculty not get bogged down by tangential concerns or launch a debate on specific OA mechanisms. At this point, our priority was getting the majority to agree on the necessity of $\mathrm{OA}$ in broad strokes. The key was finding common ground.

The unanimous passage of this resolution was our most important milestone to date. It signals a key threshold victory in gaining support for OA at UW. However, this is only the beginning. Support is foundational, but the real fight will happen as we tailor a strong policy with "teeth." Moving forward, our greatest challenge will be interacting with faculty in our role as graduate students and OA advocates. We are still figuring out how to avoid the perception that we are explaining faculty's jobs to them, and how to present opt-out mechanics in the clearest and most positive way possible. The underlying challenge throughout will be staying "at the table" in what is traditionally a student-founded, librarian-supported, and faculty-driven effort.

We also struggle with maintaining big-picture framing in the midst of small-details conversations. Faculty's concerns about-and even conflation of-copyright and intellectual property, for example, at one point threatened to derail the OA initiative. Addressing this issue required calling on the Washington State Attorney General's Office and OA legal experts like Harvard University's Peter Suber.

In another roadblock, we encountered vehement faculty criticism based on the misperception that university administration was behind the OA initiative. This was remedied by simply communicating to the faculty in question that this was a bottom-up, not top-down, coalition of students, faculty, and librarians.

Nevertheless, such simple misunderstandings can derail an initiative at any point. So far, it has been our job to check in with faculty often.
If we have our thumb on the pulse of faculty sentiment, we can address misunderstandings as quickly and comprehensively as possible.

Some of these obstacles and challenges may be unique to UW, others are not. Many students may have dealt with challenges similar to the ones in our story. Thus, particularly useful for future student advocates would be a set of guidelines - a "toolkit"-for engagement and leadership in $\mathrm{OA}$ initiatives. Existing resources like R2RC's activism and resource pages ${ }^{7}$ or HOAP's "Good Practices for University Open Access Policies" ${ }^{\prime}$ are effective starting points. But advocates still need more varied, compelling resources to convey OA to diverse audiences. High-quality graphics and video, for example, are scant. Another gap in currently available resources is a central place to find engaging anecdotes and up-to-date news (like the Diego Gomez case, OA's unfulfilled role in addressing the Ebola crisis, ${ }^{10}$ and other universities' milestones and successes) to give a larger context to OA initiatives. OA advocates need these resources in a wiki-like environment where they can engage with each other, edit content, give each other real-time feedback, and customize and remix content for their own local uses.

Additionally, stories from other students-like the one here-are just as useful. Students want to hear in detail about what their peers have done, challenges they have faced, and how they have overcome them. Giving student advocates a platform and the encouragement to speak can drive others to take action with confidence.

Ultimately, with new resources and a growing community of OA advocates convening online and in person, we believe that it is students who will continue to bring energy and conviction to OA initiatives. This can be students' primary role in the OA movement- - to bring stakeholders together, drive crucial issues of equity and representation, and shape the future of scholarly publishing in which we all hold such a vital stake. ${ }^{11}$

\section{Acknowledgements}

The authors would like to thank the following individuals for their support, guidance, and advocacy throughout this initiative: Juan Pablo 
Alperin, Thom Deardorff, Mel DeSart, Joe Janes, Tim Jewell, Heather Joseph, Ann Lally, Ben Marwick, Kate O'Neill, Alice Popejoy, Michael Rosenfeld, Nick Shockey, Peter Suber, Helene Williams, Betsy Wilson, and Austin WrightPettibone. n

\section{Notes}

1. University of Washington Fast Facts 2015 : http://opb.washington.edu/sites/default/files /opb/Data/2015_Fast_Facts.pdf.

2. Harvard Open Access Policy: https://osc. hul.harvard.edu/policies.

3. Resolution Urging the University of Washington to Adopt an Open Access Publications Policy: http://depts.washington.edu /gpss/sites/default/files/GPSSOpenAccessResolutionPASSED.pdf.

4. A Resolution in Support of Open Access to Research Articles: http://depts.washington.edu/ asuwsen/oro/\#!LegislationView/id=138457.

5. Open Access to Research Articles FAQ: http://uwopenaccess.com/policy-faq/.

6. Resolution Concerning the UW Open Ac- cess Repository and Request for Advice on an Open Access Policy: http://www.washington. edu/faculty/files/2014/05/543.pdf.

7. Right to Research Coalition activism resource pages: www.righttoresearch.org /act/index.shtml and www.righttoresearch.org/ resources/index.shtml.

8. Good Practices for University OpenAccess Policies: http://cyber.law.harvard. edu/hoap/sites/hoap/images/Bestpracticesguide-2013.pdf.

9. "Support Diego Gomez, Join the Global Open Access Movement," Electronic Frontier Foundation: https://www.eff.org /deeplinks/2014/09/support-diego-gomez -and-join-global-open-access-movement.

10. "Don't Think Open Access Is Important? It Might Have Prevented Much of the Ebola Outbreak," TechDirt.com: https://www. techdirt.com/articles/20150409/17514230608 /dont-think-open-access-is-important-it-might -have-prevented-much-ebola-outbreak.shtml.

11. Please visit www.uwopenaccess.com to learn more about the OA initiative at UW. $n$

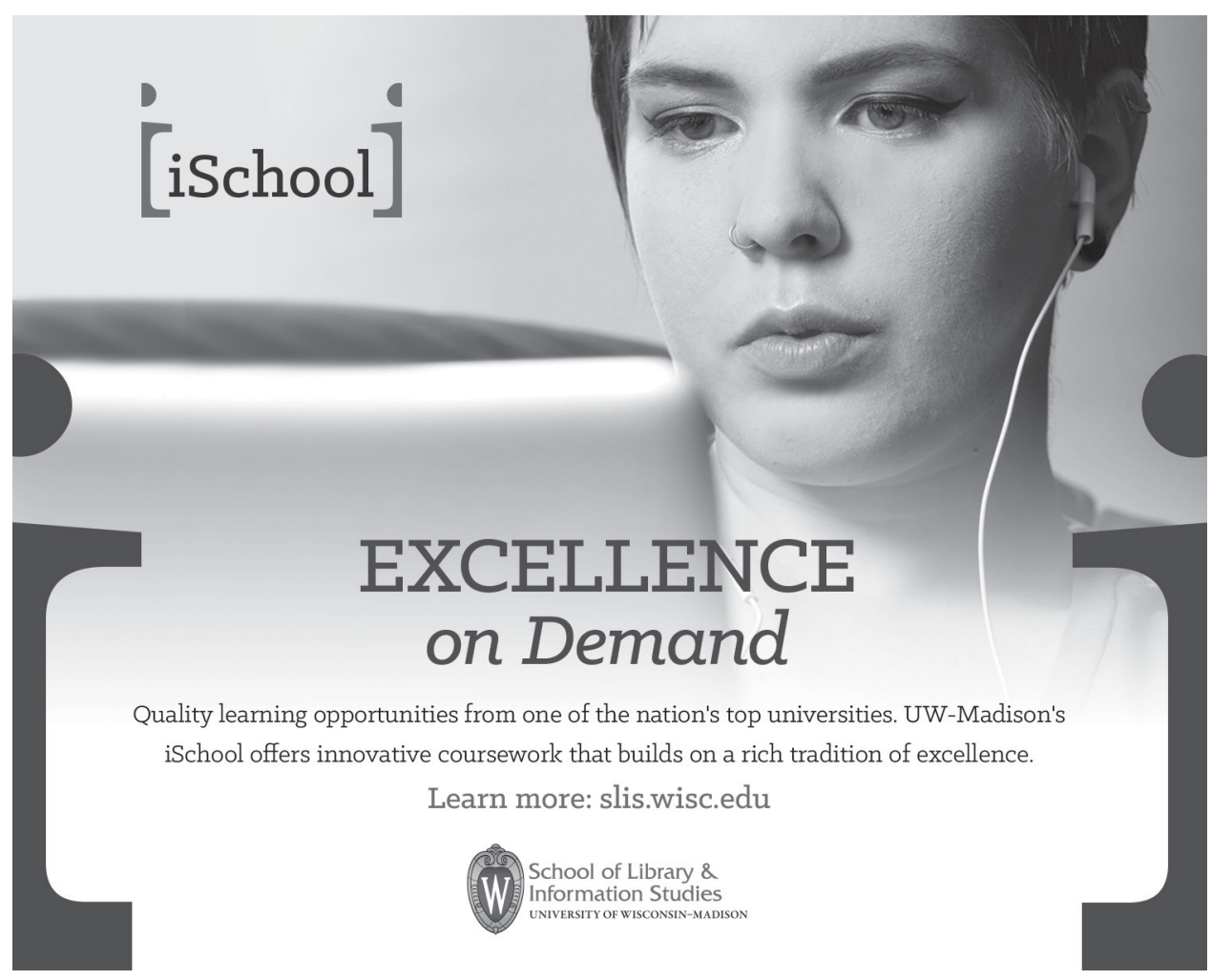

